\title{
Guilleermo
}

de Pelsham

Artículo original ๑ Acceso abierto

\section{Territorio y territorialización: una mirada al vínculo emocional con el lugar habitado a través de las cartografias sociales}

Territory and Territorialization: A Look at the Emotional Link to the Inhabited Place Through Social Cartography

\author{
Carlos Alberto Castaño-Aguirre i (i) (을 \\ Pilar Baracaldo-Silva ${ }^{\text {ii }}$ \\ Angela Milena Bravo-Arcosii (ib) (ำ \\ Joan-Sebastián Arbeláez-Caroiii (i) ()

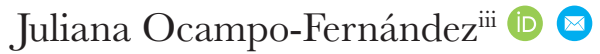 \\ Olga-Liliana Pineda-Lópeziii
}

\author{
${ }^{i}$ Programa de Arquitectura; Facultad de Artes Integradas; Universidad de San Buenaventura; Armenia; Colombia. \\ "i Programa de Psicología; Facultad de Ciencias Humanas; Corporación Universitaria Alexander von Humboldt; Armenia; Colombia. \\ iii Programa de Psicología; Facultad de Psicología; Universidad de San Buenaventura; Armenia; Colombia.
}

Correspondencia: Carlos Alberto Castaño Aguirre. Correo electrónico: carlos. castano@usbmed.edu.co

Recibido: 01/03/2021

Revisado: 04/05/2021

Aceptado: 20/05/2021

Investigación. Este artículo hace parte de la investigación titulada "Configuración de la territorialización de los habitantes de Armenia, Quindío", financiada por la Universidad de San Buenaventura Medellín y la Corporación Universitaria Empresarial Alexander von Humboldt.

Citar así: Castaño-Aguirre, Carlos Alberto; Baracaldo-Silva, Pilar; BravoArcos, Angela Milena; Arbeláez-Caro, Joan-Sebastián; Ocampo-Fernández, Juliana; Pineda-López, Olga-Liliana. (2021). Territorio y territorialización: una mirada al vínculo emocional con el lugar habitado a través de las cartografías sociales. Revista Guillermo de Ockham, 19(2), pp. 201-217. https://doi.org/10.21500/22563202.5296 Copyright: (C) 2021. Universidad de San Buenaventura, Cali. La Revista Guillermo de Ockham proporciona acceso abierto a todo su contenido bajo los términos de la licencia Creative Commons AttributionNonCommercial-NoDerivatives 4.0 International (CC BY-NC-ND 4.0).

\section{Resumen}

El territorio, la territorialización y las cartografías sociales, se constituyen como categorías que pueden aportar a la comprensión del vínculo emocional de los sujetos con el espacio o lugar habitado. Este artículo busca dar respuesta al interrogante ¡cómo las cartografías sociales permiten representar el vínculo emocional con el territorio? Se hace a partir de una revisión bibliográfica soportada en el rastreo de bases de datos de libre acceso. Una de las principales conclusiones es que el territorio se comprende como una categoría multidimensional que no solo vincula la apropiación e identificación con un espacio físico, sino que también profundiza en las construcciones sociales, políticas y simbólicas establecidas en la cotidianidad. Las cartografías sociales se convierten en estrategias de transformación social que permite a las comunidades o grupos, construir y abstraer los significados asignados al territorio y el vínculo emocional compartido entre ellos, para empoderarse como sociedad hacia el desarrollo colectivo.

Palabras clave: cartografía social, emociones, lugar habitado, territorialización, territorio, vínculo.

\section{Abstract}

Territory, territorialization, and social cartography have become categories that can help to understand the emotional attachments between subjects and the spaces/places the inhabit. This article aims to answer the question: How can social cartography represent one's emotional attachment to the territory? It further aims to make a bibliographical review based on the search of the concepts in open access databases. One of the main conclusions is that the territory is understood as a multidimensional category that links not only one's ownership 
Conflicto de intereses. Los autores han declarado que no hay conflicto de intereses.

Disponibilidad de datos. Todos los datos relevantes están en el artículo. Para mayor información contactar al autor de correspondencia.

Fondos. Sí. Código: M3879, Universidad de San Buenaventura Medellín. Código: D.I.P.03-2020, Corporación Universitaria Alexander von Humboldt

Descargo de responsabilidad. El contenido de este artículo es responsabilidad exclusiva de los autores y no representa una opinión oficial de sus instituciones ni de la Revista Guillermo de Ockham. of, and identification with, a physical space, but also delves into the social, political and symbolic constructs established in everyday life. Social cartographies become different transformation strategies that enable communities or groups to build and abstract the meanings assigned to the territory and the emotional attachment shared in between to become empowered as a society to achieve collective development.

Keywords: attachment, emotions, inhabited place, social cartography, territory, territorialization.

\section{Introducción}

Las cartografías sociales han sido reconocidas como un método que permite, de manera dinámica y visual, identificar relaciones territoriales, dando así la posibilidad de construir una gramática, un lenguaje territorial, a partir de la heterogeneidad de voces que participan en ellas (Betancurth et al., 2020; Carballeda, 2017). Los mapas develan disputas, jerarquías, cuestionamientos y prácticas propias de la cotidianidad, así como las atribuciones de sentidos en los entramados de la vida social. Para Barragán (2019) son "[...] un lenguaje que comunica a través de un conjunto de imágenes, signos y símbolos; y que representa formas de comprensión del mundo que surgen desde diferentes lugares y sujetos de enunciación, convirtiéndose en un lenguaje plural" (p. 141).

La presente revisión bibliográfica busca articular las categorías de territorio, territorialización y emociones, con el uso de las cartografías y mapeos sociales, como método para visibilizar las complejidades de la construcción social del espacio habitado. Partiendo de la pregunta ¿cómo las cartografías sociales permiten representar el vínculo emocional con el territorio? se llevó a cabo un rastreo del material académico en bases de datos científicas de acceso abierto, como Scielo, Dialnet, Redalyc y Google académico. Se tiene, como criterio de selección, la actividad científica editorial de los últimos quince ańos sobre Latinoamérica y el Caribe.

Este artículo tiene como objetivo analizar el uso de las cartografías sociales como método de representación del vínculo emocional con el territorio, y en este los procesos de territorialización, a través de las evidencias teóricas y científicas disponibles en bases de datos y fuentes primarias, como primera fase del proyecto de investigación Configuración de la territorialización de los habitantes de Armenia, Quindio. La pertinencia de las fuentes utilizadas se evaluó a partir de la confiabilidad de las bases de datos, la revista publicada y la integración de las categorías trabajadas, con el fin de responder a los interrogantes que generan las articulaciones y diálogos de estas categorías. Las palabras clave de búsqueda en las bases de datos, fueron "cartografía", "territorio", "territorialización" y "emociones y territorio". A partir de la discusión sobre el resumen o abstract, se hace una recopilación en una matriz de análisis para determinar el aporte de los artículos a la investigación, lo cual llevó a la selección de 49 documentos que fueron incluidos. La revisión bibliográfica es el sustento teórico y metodológico de la investigación en marcha y desde la cual se desarrolla el presente escrito.

Para dar cuenta de la forma como los individuos y las comunidades dan significados colectivos a los espacios que habitan, transitan o interactúan en la cotidianidad, y sobre ello construyen una cognición que les permite interactuar con el mundo externo, sus objetos físicos y sus construcciones sociales, es necesario explorar el uso de herramientas que accedan al conocimiento y la intervención de los propios sujetos involucrados en el territorio, y adecuarse a las condiciones particulares de estos, contribuyendo y revelando las encrucijadas entre lo real, lo imaginario, las subjetividades y la otredad. De acuerdo 
con Osorio y Vergara (2016), hablar de cartografías desde las emociones permite la creación de "un mapa mental a partir de las sensaciones y emociones generadas tras vivir una experiencia. Dichos mapas dan a entender cómo una persona percibe el espacio en el que se encuentra, cómo lo siente y cómo se familiariza con este" (p. 35). Es, precisamente, en esas experiencias, percepciones y sentires, que se constituyen los vínculos territoriales y el interés en recabar en ellos mediante el dibujo y las recreaciones del espacio habitado.

A partir del hecho de que tanto territorio como territorialización no son conceptos estáticos, sino, por el contrario, objetos dinámicos en la interacción humana, se ha encontrado en la literatura el uso de la cartografía social como estrategia de acceso a lo que surge en dichos espacios, pero también como forma de agenciamiento de los grupos sobre las problemáticas que emergen en dichas interacciones: sociales, políticas, económicas, temporales y socioculturales. El texto está organizado en tres apartados principales. El primero, la definición y reflexión frente a territorio, argumentando la relación que los individuos establecen con dicho objeto. Luego, la conceptualización sobre territorialización, que circunscribe una serie de valores, emociones y experiencias que determinan dicha relación entre los individuos y entre individuos y el lugar. Y por último, la definición de cartografía social que desde algunos estudios empíricos busca visibilizar el uso metodológico de dicha estrategia bajo el enfoque participativo.

\section{Territorio}

Hablar de territorio conlleva revisar diversas aristas, así como pensar y organizar varios elementos para acercarse a un concepto que está en constante evolución, pues en esencia, el territorio es un constructo que acompańa al sujeto y que guarda una influencia trascendental en todos los procesos que a este atañen. Generalmente, el territorio se ha asociado a la ubicación geográfica de un sitio, ligado también al establecimiento de relaciones de poder en las comunidades y en el Estado propiamente dicho. Sin embargo, hablar de territorio con base en esta concepción es reducirlo y limitarlo, desconociendo, además, otras dimensiones como la cultural, la ambiental, la sociológica, la económica y la antropológica que lo caracterizan. Dentro de las múltiples definiciones se resalta que, para disciplinas como la geografía, el territorio es el espacio de gobernanza, en el cual los gobiernos desarrollan su gestión (Fernandes, 2012) y para la psicología, el territorio se vincula con la identidad personal construida por el individuo y que al final lo lleva a construir también su identidad social (Gaviria-Ríos, 2020).

A partir de reconocer estas dimensiones en su definición, el territorio se convierte en un espacio construido socialmente, que vincula la historia y los procesos económicos, políticos y culturales. Además, se organiza con base en las relaciones que establecen quienes lo habitan, relaciones que, en muchas ocasiones, lo configuran y le dan sentido e identidad (Gaviria, 2020). Así pues, el territorio es un concepto construido, creado a priori por una comunidad, que busca ser materializado según las condiciones históricas y sociales, apoyadas por las emociones (Vergara, 2012). Al vincular el aspecto emocional, se entiende, además, que el territorio no puede ser concebido como un constructo finalizado y estático, pues este componente, forjado en las relaciones de las personas entre ellas y con el territorio, delimita una mirada amplia, cambiante y relevante a la hora de aproximarse a su definición.

La conceptualización de territorio está ligada a construcciones asociadas al espacio y a palabras como lugares, sitios y paisajes, entre otros. Estos se vinculan, por lo general, a una condición espacial que parece ser esencial en la vida de las personas. Así entonces, el territorio puede definirse como el concepto mediante el cual se representa o significa el espacio y se resaltan sus características y propiedades. Hablar de territorio no es igual que 
hablar de tierra, por lo cual no puede medirse ni contarse (Vergara, 2012; Nates, 2011). Esta definición involucra las construcciones que los sujetos efectúan de esa condición espacial representada en el territorio, permeada por las emociones, los sentimientos, los símbolos, las vivencias, los anhelos y los sueños, lo que hace que el sitio que se habita se convierta en una parte de sí mismos y, en alguna medida, en parte de su identidad personal y social.

Es, precisamente, en esos espacios habitados donde coexiste una realidad subyacente superior a la realidad material, tangible y física, lo cual podría asociarse con el concepto de territorio material e inmaterial propuesto por Fernandes (2017). En este sentido, si se quiere conocer la configuración de estos espacios y territorios, es preciso incluir fundamentalmente las experiencias construidas, manifestadas mediante la memoria histórica de quienes los habitan. Esto, quizá, es la invitación a repensar la necesidad de vincular la teoría del afecto y la importancia de las emociones en la comprensión de los lugares y territorios (Aubán, 2017).

El espacio acude al concepto de representación como elemento fundamental para entender las acciones y los movimientos que se gestan en el territorio. Sin embargo, es pertinente aclarar que existe una diferenciación entre espacio y territorio. El primero es la base del segundo. "El territorio se basa en el espacio, pero no es espacio. Es una producción desde el espacio" (Santos da Rocha, 2013, p. 139). Con lo anterior se da claridad frente a la necesidad de significar el territorio vinculando sus componentes, pero dejar de reconocer las diferencias que existen en la concepción de estos. Puede entenderse, además, que el espacio se convierte en una categoría de mayor amplitud que permite incluir al territorio para comprenderlo y definirlo.

Como se ha visto con anterioridad, el territorio es un fenómeno geosociohistórico, multidimensional (Gaviria, 2020) y en términos de Nates (2011), multiescalonado. Esta dimensionalidad debe ser entendida a la luz de las diferentes esferas que componen al sujeto, integrando, además, una concepción de él con base en lo biopsicosocial y configurando la relación entre la realidad concreta y geográfica, la psiquis, en la cual se establecen las relaciones emocionales con el territorio y las representaciones sociales, culturales y colectivas que se producen en él. En este sentido, es importante destacar lo descrito por Fernandes (2012), cuando resalta el papel de las relaciones sociales en la configuración de los territorios y a su vez, la presencia del conflicto dentro de las propias dinámicas de estas relaciones. La conflictividad es un proceso constante que produce, a partir de la diversidad misma, diferentes espacios y territorios.

Dada la amplitud de connotaciones que constituyen el territorio, es de anotar que este se enfrenta a los cambios producidos por las sociedades modernas. Procesos como la globalización, el desarrollo tecnológico y los cambios sociales, permean la organización espacial de las ciudades y territorios, lo cual genera nuevas conceptualizaciones, como la denominada ciudad-región, en la que se integran los rasgos diferenciales frente a lo que tradicionalmente se conocía como ciudad, uniendo de esta manera nuevos espacios y vínculos funcionales entre las ciudades geográficamente cercanas y de diferentes tamaños. La definición de ciudad-región va más allá de la delimitación geoespacial y se articula con el intercambio e interacción a nivel social, cultural y económico. Estas ciudades se favorecen por la proximidad geográfica presente entre ellas (Gaviria, 2020). Este y otros fenómenos que surgen a partir de la influencia de los procesos y dinámicas de una sociedad cambiante, se convierten en elementos que amplían la concepción, la conceptualización y la comprensión de lo que es el territorio. 
De acuerdo con Fernandes (2012), cuando se abordan los cambios y procesos dentro de los territorios, se debe hablar de la conflictividad dada por los actores sociales, desde la cual el autor propone una tipología de los territorios para profundizar este concepto a partir de un análisis multinivel y multidimensional. Dentro de la tipología presentada para definir el territorio, se identifican un primer, segundo y tercer territorio. El primero se constituye como el punto de partida para que los pueblos existan. El segundo territorio vincula los conceptos de propiedad en el cual se ubican innumerables conflictos asociados a las disputas territoriales, y el tercer territorio es delimitado como el espacio en el que se visibilizan las relaciones dadas a partir de la conflictividad y reúne todos los tipos de territorios. Fernandes (2017) resalta, además, que se precisa definir no solamente un concepto general de territorio, sino también los tipos de territorio, sobre la base de que las relaciones sociales producen y se producen a partir de estas tipologías.

Al hilo de lo anteriormente descrito frente a la configuración de los territorios y del surgimiento de nuevos términos y formas de comprender la dimensión de los espacios, se evidencia la importancia de factores como la comunicación para el establecimiento de las relaciones que determinan en muchos casos la noción del territorio. Para Cuesta y Mélendez (2017), la ciudad, entendida como una manifestación del territorio, se concibe como el espacio donde ocurren los procesos comunicativos. Esta comunicación puede estar integrada por categorías como el discurso, el lenguaje, los medios de comunicación y las interacciones sociales, los cuales permiten comprender las dinámicas de la ciudad como espacios que facilitan las relaciones socioculturales y como el espacio de prácticas sociopolíticas. Aunada a la comunicación, la tecnología es otro de los elementos que permean los territorios, en tanto que las ciudades empiezan a involucrar en su caracterización los procesos de innovación tecnológica, esto puede generar o aumentar las desigualdades sociales y espaciales en las ciudades, lo cual es característico de las sociedades actuales (Mendes, 2014).

El territorio lleva a generar espacios y eventos que marcan la relación de las personas con él. Un caso por resaltar es el presentado en Atenco, México, donde las mujeres, mediante la lucha política por la defensa de la tierra, logran modificar la relación específicamente entre mujeres, el territorio y los territorios. Esto facilita la construcción y transformación de sus relaciones y comunidades, incluidas las relaciones de género, y en un especial apartado, el cuerpo, como parte del territorio. En una línea similar, las comunidades, por lo general oprimidas, generan prácticas que permiten construir resistencias, nuevos significados y transformación de las realidades vividas por ellas en los territorios (Quintana, 2019; Moreno y Mornan, 2015).

Dentro de dichos procesos y eventos suscitados entre los sujetos y el territorio, está inmerso el vínculo entre territorio y naturaleza, el cual, en ocasiones, no es reconocido, generando así un alto grado de desconexión. La ciudad depende de un entorno mayor que el de su propio territorio para garantizar aspectos fundamentales, como el sustento de sus habitantes (Garavito y De Urbina, 2019). La vinculación del sujeto con el territorio es un proceso en el cual se requiere contemplar, además, la presencia y participación de otras especies y elementos del medioambiente, por lo cual estos procesos que involucran la conexión emocional con el territorio, van más allá de una actividad exclusivamente humana (Skewes et al., 2017).

El afecto y la vinculación afectiva con los lugares es una categoría que merece un apartado especial, dada la importancia que denota en la comprensión del territorio. En un primer momento, se afirma que las emociones y sentimientos hacia un lugar o territorio se deben evaluar desde diversas dimensiones, como por ejemplo, el vínculo comunitario, social, cultural y el suscitado por ambientes naturales, entre otros. También se requiere 
considerar que las emociones están influenciadas y se construyen a partir de la creación de significados sociales, lo cual permite comprender de qué forma las personas sienten apego por un lugar o territorio y, finalmente, se requiere incluir en el análisis y comprensión de la relación entre emoción y territorio, las prácticas materiales denominadas vivencias, pues estas prácticas cotidianas crean estas vivencias y una interpretación de la realidad por quienes la viven y construyen (Berroeta et al., 2017).

Para aproximarse a la lectura de las relaciones de afecto y a los vínculos afectivos que se establecen con el territorio, es indispensable incluir el concepto de comunidad, desde el cual se dan las bases para analizar las relaciones entre los habitantes de un territorio, las cuales son complejas y particulares (Figura 1). Los habitantes de un determinado territorio son las piezas fundamentales en el establecimiento de las relaciones, que en muchas ocasiones posibilitan el establecimiento de vínculos afectivos con él. El territorio no puede concebirse como algo natural, pues se manifiesta como producto social dado a partir de las construcciones que van más allá del espacio físico habitado por alguien o por una comunidad. Esto permite afirmar que el territorio es, en gran medida, una creación de la sociedad, asociado al sentido y a la apropiación del espacio dados por quienes lo habitan (Aubán, 2017; Vergara, 2012).

\section{Figura 1}

Elementos asociados al territorio

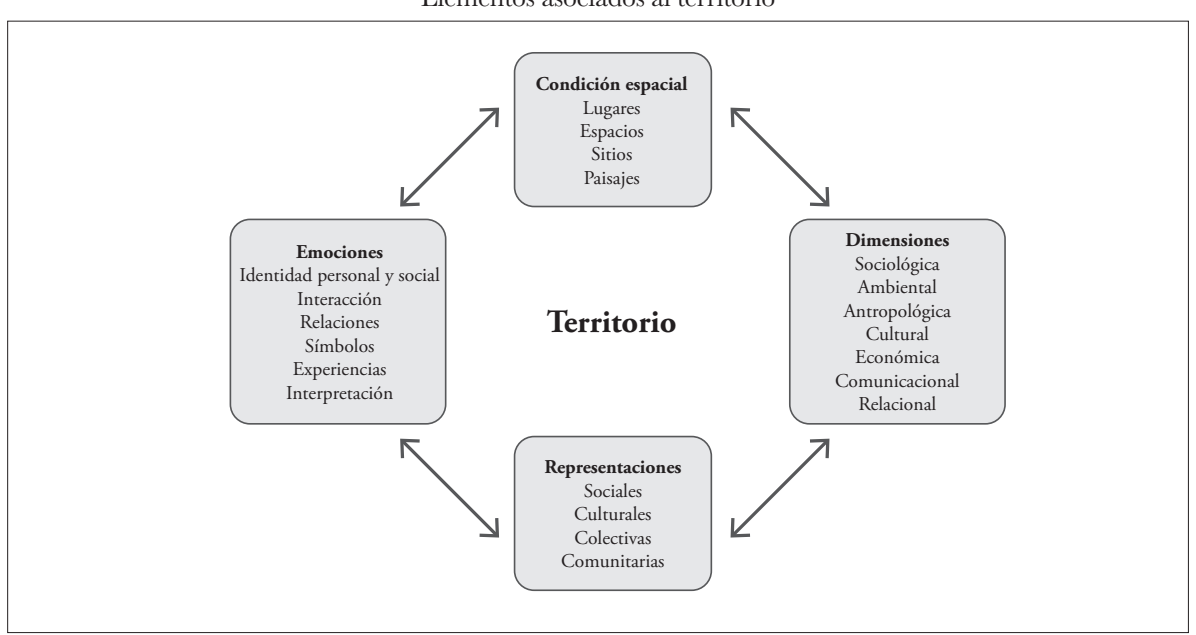

Fuente: elaboración propia a partir de Gaviria, 2020; Vergara, 2012; Aubán, 2017; Cuesta y Mélendez, 2017

\section{Territorialización}

La territorialización es asociada a un proceso en el cual un sujeto, comunidad o grupo social apropia y se vincula con un lugar físico (López y Figueroa, 2013; Tobasura et al., 2019; Zapata, 2008), en cuanto el espacio geográfico es marcado con las experiencias, memorias y la producción de sentido de los sujetos en un momento determinado. La territorialización se soporta en la relación espacio-tiempo, lo cual hace que sea dinámica y se transforme de acuerdo con el contexto social, cultural y político.

En términos de Vite (2011), citando a Hernández Cordero, en el proceso de territorialización se presentan varios niveles: la morfología y configuración del espacio, que hace relación a lo tangible, a lo construido físicamente, a la forma-objeto. Otro nivel son las relaciones sociales, en las cuales se dan las interacciones y el entrecruzamiento de sujetos en las diferentes capas físicas. Y por último, la estructura social, la cual corresponde a los sentidos o significados que se les dan por parte de un grupo social a las formas construidas, a la forma-contenido. 
No obstante, en estos niveles de territorialización es necesario ver cómo el espacio es semantizado por quienes habitan; esa constante tensión entre significaciones colectivas, normalizadas y aceptadas socialmente, y el sujeto que interpreta y, en algunos casos, hace resistencia a estas. Para Zapata (2008), la territorialización, vista como espacio significado, posibilita la comprensión de

[...] seńales que condensan realidades, percepciones y actitudes frente al contexto, comunicando el sentido que ponen allí quienes lo habitan; es entonces el resultado de las representaciones sociales, de lo reconocido y socializado, de lo que hace referencia a las prácticas sociales del territorio mediante un discurso no verbal. (p. 334)

Desde la teoría del ensamble citada por Tobasura et al. (2019), el espacio es establecido de manera racional. Es una producción que involucra categorías sociológicamente importantes no predeterminadas por la posición histórica, sino por las transformaciones visibles generadas por las cambiantes relaciones espaciales resultantes de las disputas, resistencias, supervivencias, alianzas y acuerdos, propios de la vida cotidiana. Es, precisamente, este proceso de conformación de identidades, límites, materialidades, corporalidades e interacciones espacio temporales, lo que se plantea como territorialización.

Dicho lo anterior, el espacio es socialmente construido a partir de las relaciones y maneras de sujetarse al mundo de un grupo social específico y en un momento y lugar geográfico específicos. En ese proceso de construcción se dan interacciones de convivencia armónica o conflictividad antagónica que permiten filiaciones por un lugar, así como topofilias y topofobias. Para Medel y Montre (2018), la topofilia puede entenderse como el lugar donde las personas se sienten ligadas consigo mismas, con el entorno y con las otras personas que habitan. Habitando se cargan de significancia los espacios. Por otra parte, la topofobia se relaciona con los lugares en donde estar es desagradable para los habitantes. Los espacios no solo están constituidos de sentimiento positivos, sino que también generan y cargan sentimientos negativos, normalmente definidos como espacios peligrosos que proyectan miedos e inseguridades y por ende provocan rechazo.

Cabe mencionar que cuando se habla de philia-ción, Yory (2017) plantea que se alude a la propia construcción del espacio en el acto de habitar, lo cual

[...] exige entender la construcción del espacio, que corresponde con la mostración de ese ser-en-el-mundo del que venimos hablando, como una construcción topofílica de territorio; toda vez que la clase de fundación a la que nos referimos, es siempre, en tanto implantación, una "marca en el suelo" o, lo que es lo mismo, una territorialización. (p. 119)

Una de las contribuciones de la topofilia como teoría del lugar, es resaltar la dinámica relación entre espacio físico y sujetos. El espacio no es un caparazón contenedor de interacciones sociales o a la espera de ser cargado con las emociones humanas, sino que también determina y condiciona maneras de ser en el mundo. Hay una constante tensión entre sujetos y lugar, en la que el sujeto marca con su diario vivir el lugar, pero a su vez es marcado también por él.

Sin embargo, ni los sujetos, ni los lugares, ni las relaciones que se dan entre estos, son estáticas o inmaculadas. Por el contrario, están en constante transformación, regeneración, mutación y desaparición, lo que constituye una relación dialéctica entre procesos de desterritorialización y reterritorialización (Bendini, 2011; López y Figueroa, 2013; Giménez, 2005; Portilla, 2014), evidenciada en hechos como la movilidad humana, en la cual, por un lado se da una salida y abandono de un lugar originario, pero por el otro, esto conlleva una llegada y un nuevo proceso de apropiación por el territorio receptor. De acuerdo con esto, se da la desterritorialización porque hay una reterritorialización del sujeto. No hay una sin la otra, ni tampoco son absolutas. 
Se trata de un vínculo dinámico, sujeto a múltiples procesos y, por ende, no puede ser una relación fija, inamovible o estática. Con base en ello afirmamos que los fenómenos de pérdida, recuperación, acercamiento, alejamiento, conocimiento, desconocimiento y reconocimiento se sintetizan en los procesos de desterritorialización/reterritorialización. (López y Figueroa, 2013, p. 175)

Es, precisamente, en estos diálogos entre desterritorialización/reterritorialización que se constituye la multiplicidad de territorios y son los diálogos también producto de las complejas relaciones entre sujetos, sistema de ordenamiento social y geografías (Feldman, 2017). Lo que es ampliado por Haesbaert (2013), al enunciar que el territorio es concebido por las relaciones de poder construidas en y con el espacio, lo que lleva a que la desterritorialización/reterritorialización tenga efectos diferenciales. Por una parte, se encuentra lo que el autor denomina multiterritorialidad segura, cuando los procesos de reterritorialización se dan bajo mayor control de los sujetos (una elite globalizada); y por la otra, la precarización territorial, cuando se da una desterritorialización forzada y los sujetos reterritorializan como proceso de resistencia y lucha por un espacio mínimo cotidiano y una seguridad en él.

En ese sentido hay un componente político que entra en juego, ya que todo proceso de apropiación es resultado de las relaciones de poder, las significaciones y luchas por el sentido que se dan en un lugar específico (López y Figueroa, 2013), sin desconocer que en el territorio hay incidencias a diferentes escalas y una geopolítica que propicia ciertas condiciones. Para Feldman (2017), hay tres niveles de territorialización, a saber, lo local, lo regional y lo global. Sobre esto cita a Deleuze y Guattari:

Sin perjuicio de las definiciones de estos tres niveles, todos ellos están presentes en un territorio dado, ya que las relaciones que se conforman parecieran demarcar una multiplicidad presente en todos los procesos de territorialización que se traduce, también, en multiplicidad identitaria. (p. 90)

A partir de de esto, cuando se habla de construcciones identitarias como elementos presentes en los territorios, es recurrente encontrar el concepto de territorialidades, las cuales están enmarcadas en dinámicas de disputas y conflictos, acuerdos y desacuerdos, en el reconocimiento por la otredad y en el autorreconocimiento, lo cual propicia acercamientos o distancias de unos sujetos o grupos de sujetos con otros (Díaz, 2015).

Según Monnet (2013), en las reflexiones acerca del territorio se puede hablar de un sistema socioterritorial en el cual se da la triada territorio, territorialidad y territorialización (Figura 2). Es una nueva mirada sociocéntrica que renueva la conceptualización del territorio como espacio meramente físico y lo pone como sistema de producción del ser humano.

Figura 2

Relaciones entre los conceptos de territorio, territorialidad y territorialización

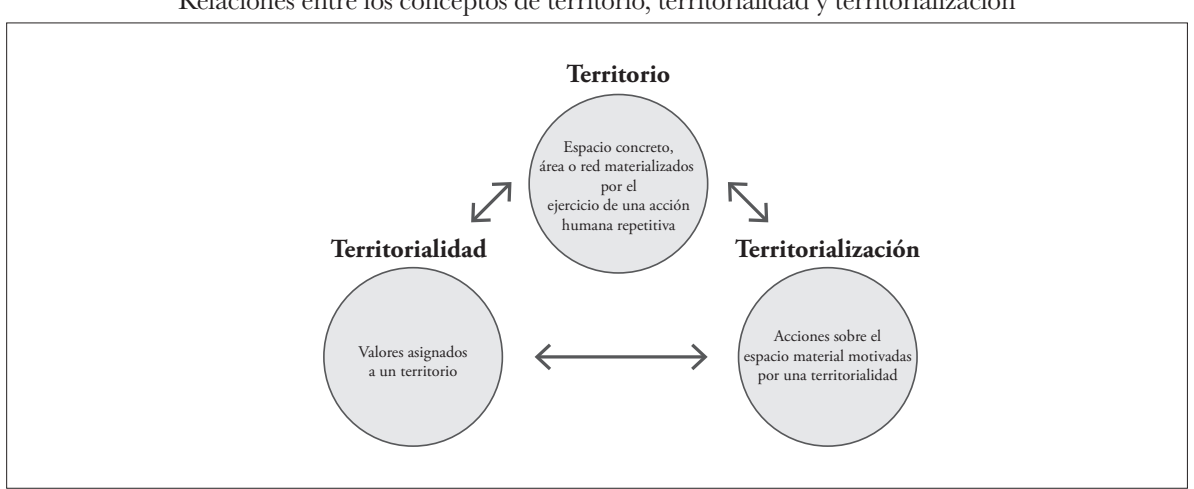

Fuente: elaboración propia a partir de Monnet (2013). 
Los conceptos de territorialidad y territorialización son derivados del territorio. Este, como ya se ha mencionado, se conceptualiza como un espacio construido socialmente en la apropiación por parte de los sujetos que habitan. Es una producción compleja y multidimensional en la que la territorialidad se plantea como sistema relacional mediatizado, simétrico o asimétrico, que mantiene una colectividad (y sus individuos) con la exterioridad y la alteridad. Por otro lado, la territorialización es definida como la apropiación en dos frentes, material e ideal, de una porción de espacio físico-geográfico por parte de un grupo social o colectividad. En otras palabras, una dualidad entre lo concreto y los abstracto, en la que lo abstracto hace referencia a la representación de un lugar (Stamm y Aliste, 2014).

Otro aspecto que entra en diálogo en los procesos de territorialización es el sentido de lo propio, el pertenecer a un lugar. Rojas (2018), plantea el concepto de emoterras (sistemas de emociones vinculadas al territorio), las cuales están relacionadas con el sentimiento de pertenencia de los territorios y articula cuatro categorías: emociones, territorio, actores y tiempo, y destaca que en los encuentros entre ellas se dan la objetivación y la subjetivación, lo cual involucra al debate el emplazamiento de objetos como manera de territorializar las emociones y las acciones y prácticas sociales conmemorativas de sucesos significativos para cierto grupo social en los que se experimentan las emoterras.

Comprender la territorialización como un proceso en que actúan sujetos, el lugar y los objetos en un contexto específico, requiere retomar lo planteado por Covarrubias y Cruz (2019): "Los objetos exteriores son representaciones sensibles en el espacio y en el tiempo y, por lo tanto, fenómenos y no cosas en sí” (p. 89). Por ejemplo, la invención de la bombilla eléctrica requirió la construcción de infraestructura, sistemas de alumbrado, señalizaciones y adecuación de las viviendas, entre muchas otras dinámicas. Las maneras de ser de los sujetos y su relación con el mundo cambiaron. Los objetos no están aislados de esa construcción social del territorio, sino que, por el contrario, a través de ellos se significa, apropia y constituyen formas de habitar un lugar.

Sumado a lo anterior, según Cejas et al. (2017), los objetos se han trabajado en su relación con los sujetos. Sin embargo, al hablar de vínculos sociales se hace la asociación de "lo material" con los objetos y "lo social" con los sujetos, lo cual para los autores es una postura típicamente moderna, sobre lo que proponen

[...] abordar la relación entre personas y objetos tanto en su dimensión material como en la social/cultural/simbólica, ambas constitutivas de ese vínculo. Decimos que no es posible comprender las relaciones de poder y dominación si no atendemos la materialidad (humana y no humana) de esas relaciones y, allí, el modo específico en que ellas se vinculan, se concatenan, en cada situación o coyuntura. (p. 6)

La subjetivación, entendida como prácticas conmemorativas (Rojas, 2018), se hace evidente en los procesos de apropiación social del territorio y en la territorialización y conlleva "mitos diversos y su sacralización - por medio de ritos, festividades, costumbres y tradiciones, ciclos vitales de producción o de reproducción social- hasta reivindicaciones y resistencias, expolio o despojo, así como formulaciones y estrategias políticas cuando representan intereses y proyectos diferenciados" (Díaz, 2014, p. 5).

En ese orden de ideas, los rituales, fiestas y conmemoraciones forman parte del vínculo que se construye entre sujeto y territorio, no solo por los sentires y emociones que estos generan, sino también por la carga simbólica e identitaria que representan. Ciertos ritmos, creencias, maneras de vestir, actividades en la celebración, etc. caracterizan un lugar y delimitan unos territorios de otros. Para Miñana (2008): 
En la fiesta y en la música los grupos sociales e individuos negocian y consolidan poderes, expresan y construyen procesos de identificación y diferenciación, se apropian simbólicamente de los territorios, consagran antiguos y nuevos estatus, jerarquías y liderazgos, reordenan y resignifican tiempos y espacios. (p. 143)

En la producción social del territorio, donde se dan procesos de territorialización, están inmersas relaciones de poder que constituyen, dinamizan y se manifiestan en él (Bendini, 2011; López y Figueroa, 2013; Feldman, 2017; Manzanal, 2014; Tobasura et al., 2019). Estas predeterminan espacialidades, corporalidades, materialidades y subjetividades propias de unas maneras particulares de organización social piramidal en la cual se consolida la dominación y el despojo de unos determinados sujetos o grupos sociales frente a otros, haciendo de la territorialización una constante tensión y confrontación entre intereses opuestos, así como articulaciones de intereses comunes.

\section{Cartografía social como representación del territorio y la territorialización}

De la necesidad de explorar, estudiar y entender las relaciones de las personas con el territorio, nace una estrategia investigativa que permite acercarse a la comprensión de dicha relación, de las emociones que allí emergen y sobre todo de la forma como estas se construyen. La cartografía social o cartografía participativa, como se encuentra en la literatura, se convierte en el mecanismo para acceder a dicho concepto, aplicado, vivido y narrado por los grupos sociales que ocupan, viven o transitan los territorios.

La cartografía social es el resultado de la combinación de la investigación participativa y el conocimiento geográfico de los grupos sociales, a partir de la utilización de mapas como mediadores entre la dialéctica de las personas. Se busca indagar el conocimiento y las habilidades espaciales, las representaciones, percepciones, significados, historias, problemáticas, posibilidades de transformación, configuraciones sociales y las emociones que surgen con relación a los espacios físicos (Pájaro y Tello, 2014). Es una herramienta utilizada, incluso, para ejercicios de planeación participativa, en los cuales puedan tomarse decisiones sobre el desarrollo territorial (Osorio y Rojas, 2011).

Si bien el uso de mapas ha sido una práctica tradicional en la historia de la humanidad y en disciplinas como la geografía, las ciencias sociales, al trabajar conceptos como el de territorio, usan la cartografía como una forma de acceso a la experiencia geográfica sensible, determinada por unas prácticas ciudadanas, unas prácticas socioculturales y unos significados de los territorios y sus memorias. Esto bajo la premisa de que quienes viven en los territorios son quienes lo conocen y quienes pueden construir un mapa (Pérez et al., 2018).

Por la posibilidad de participación, de darles el lugar de agencia a los actores sociales de una comunidad frente a su territorio, la cartografía social, para Habegger y Mancila (2006), se constituye como una propuesta conceptual y metodológica humanista y humanizadora, al utilizar instrumentos vivenciales elaborados por la comunidad para plasmar los saberes, deseos, ilusiones y planes colectivos y legitimarlos a partir de los mapas. Desde sus inicios, los mapas tienen el objetivo de orientar o dirigir hacia una ruta, así que la aplicación de este concepto a una estrategia metodológica mantiene dicha lógica en la orientación de un territorio físico a partir de la acción colectiva de sus habitantes, en donde hay una valoración de lo físico, pero sobre todo, de su representación y simbolismo.

Como técnica de investigación en la cartografía social, se da un intercambio de información que se asume como una coconstrucción del territorio, en el que el mapa es un medio pero no el fin. Pone de manifiesto la relación dialéctica entre individuos y territorio 
y los investigadores solo asumen su papel de observadores en el análisis del contenido que surge en las actividades de interacción (Pájaro y Tello, 2014; Pérez et al., 2018).

Barragán (2016) propone una clasificación de tipos de mapas que se pueden construir a partir de la cartografía social en la interacción comunitaria. Estos son:

- Mapa ecosistémico poblacional, un tipo de mapa que lleva a la integración comunitaria y a la generación e integración de vínculos

- Mapa temporal-social, que lleva reconstruir las memorias de la comunidad a partir de lo ocurrido en el pasado, lo que pasa en el presente y a la representación del futuro

- Mapa temático, dirigido a identificar problemáticas y riesgos con el fin de tomar decisiones para la transformación.

En este sentido, Barragán (2016) y Montenegro (2019), hacen énfasis en lo participativo y proponen unos criterios para que dicho ejercicio suceda. Tal es el caso de que los mapas se elaboren en torno a un objetivo común y la participación de la comunidad sea alta. Es importante también, que dicho ejercicio pueda evidenciar un ideario comunitario y represente elementos identitarios y características prioritarias para los habitantes, e, igualmente, que puedan trazarse en ellos rutas, lugares, nombres y objetos importantes que lleven a la comunicación efectiva.

A partir de entender la cartografía como una técnica de investigación participativa que permite el diálogo y la construcción para la transformación, se revisaron algunas investigaciones en Latinoamérica, en las que se indagaba, principalmente, por territorio y la territorialización, con el fin de dimensionar dicha relación metodológica y comprender con una mirada investigativa, la forma como las cartografías dan cuenta de los vínculos emocionales con el territorio.

En Colombia, Vélez et al. (2012), indagaron y analizaron los conflictos socioambientales relacionados con el cambio del uso del suelo en la cuenca del río Cauca entre 1950 y 2011, abordando las relaciones sociales y las prácticas existentes durante la historia en dicho escenario, a partir de la participación de tres comunidades locales. Para esto llevaron a cabo diferentes talleres cartográficos y de memoria histórica durante un periodo de tres meses, y encontraron que los principales conflictos se generan en relación con la minería, los cultivos ilícitos y las obras energéticas. En dichos ejercicios lograron integrar instituciones, líderes sociales y medioambientales, organizaciones de impacto para la región y distintas generaciones de habitantes. En el desarrollo metodológico, ejecutaron líneas de tiempo sobre los cambios ambientales a partir de diferentes voces: con los adultos mayores reconstruyeron la historia, el territorio antes; posteriormente, con mapas elaborados por jóvenes y adultos, evidenciaron las características del territorio en la actualidad; y finalmente, con niños y niñas se generaron mapas proyectados hacia el futuro, la forma como ven la transformación más adelante.

Por otra parte, abordando la temática del desplazamiento forzado a causa del conflicto social y armado en Colombia, Bernal (2012) describió y analizó las representaciones y los imaginarios del pueblo indígena nasa ubicado en Bogotá, así como sus prácticas y formas de organización comunitarias y familiares. A partir de múltiples actividades de observación participante y etnográfica, diálogo de saberes y cartografía social, se indicó la percepción de lo simbólico del territorio de sus lugares de origen y se logró promover la participación de los indígenas frente al espacio urbano y la construcción de nuevas representaciones simbólicas en los lugares de interacción. La intención de usar la cartografía fue la construcción de conocimientos que permearan contextos cotidianos que pudieran construir sobre el territorio, si se tiene en cuenta que este es un grupo proveniente del suroccidente 
colombiano que se ubica en la capital luego de vivir procesos de desplazamiento forzado, despojo o búsqueda de condiciones de vida favorables. Sin embargo, "en la ciudad, los indígenas conservan un sentido de arraigo a su territorio ancestral y a sus autónomas formas de organizarse: crean y desarrollan redes de interacción en la ciudad con sus comunidades de origen y recrean sus tradiciones culturales que los diferencian del resto de la población capitalina” (como se citó en Bernal, 2012). Esto representa una relación directa con el territorio del pasado que busca mantenerse en el presente y una emoción mediada por el arraigo a su identidad determinada por el territorio indígena de origen.

En relación con el territorio frente al desplazamiento forzado a causa de violencia sociopolítica, Quiñonez (2011) efectúa una investigación acción participativa (AIP) con el objetivo de acompañar a las comunidades de la isla de Cascajal, en Buenaventura, en el proceso de reubicación urbana en la ciudad de Cali. Utilizó la cartografía social en el marco de una investigación etnográfica con el propósito de llevar a la comunidad a desarrollar capacidad de autogestión, lo que les permitió a los involucrados avanzar en la configuración de participación frente a su nuevo territorio. Se llevaron a cabo actividades que incluyeran a toda la comunidad y se levantaron espacios dialógicos para lograr acuerdos y toma de decisiones en beneficio de todos. Propusieron para esto mapas de conflictos, de confianza institucional y de redes sociales, lo que favoreció el conocimiento e integración de múltiples actores sociales y la organización comunitaria, así como el empoderamiento frente a la participación ciudadana.

Asumir los territorios como espacios vivos, propios y con sentido de desarrollo social, permite que las comunidades puedan generar espacios de participación propias. La cartografía social comprende en este caso, la identificación de los actores sociales frente a dicha temática y el favorecimiento de la organización comunitaria. En este sentido, Betancurth et al. (2020), evidencian el uso de cartografía social como método para el estudio de activos en salud a nivel comunitario de una ciudad de Colombia. Dichos activos se constituyen en las acciones de personas, familias y comunidades frente a su estado de salud. A partir de la elaboración de mapas, recorridos por los barrios e identificación de sonidos, olores y conflictos, se logró vivir la experiencia de la cartografía de manera móvil y altamente participativa. Dichos ejercicios llevaron al análisis de la situación de salud y al papel que desempeñan los habitantes de la zona frente a dichos procesos. Esta información es fundamental para la formulación y evaluación de políticas públicas en salud.

Con una mirada diferente del territorio, Ther y Valderrama (2012), analizan las transformaciones socioeconómicas y ambientales de las caletas de pescadores chilenos producto de la inserción de la economía internacional, lo cual ha afectado ampliamente el sector, pero también la relación que tienen dichas personas con su territorio, conocido comúnmente por ser apto para la pesca. Utilizaron la cartografía social, encuestas sobre la economía y entrevistas a profundidad, para comprender este fenómeno e identificar los conflictos que se generan en este cambio laboral, económico y territorial. A partir de la elaboración de mapas de la mano con los pescadores, se visibilizaron los cambios en el uso del espacio de la playa y las dinámicas de comercialización y de organización de los pescadores gracias a la alta presencia de turismo. Esto lleva a tener presente el impacto medioambiental que dichos movimientos han generado en la práctica de la pesca y en la ubicación de los animales en el océano. Igualmente, se reconoce la llegada de otros pescadores de diferentes zonas del país, con quienes tienen conflictos por los lugares aptos para pescar, sobre la demanda de pescadores y las dificultades en la organización social y de sindicato.

Adicional al territorio y a la territorialización, pueden encontrarse múltiples temáticas asociadas a la cartografía social como estrategia de investigación y la búsqueda de transfor- 
maciones sociales a partir de la participación, y asuntos como los procesos pedagógicos, las formas de cuidado basadas en lo comunitario, la conservación del medioambiente, los objetos patrimoniales, las corporalidades, las formas de representación del poder y las memorias e identidad social, entre otros. Resulta recursivo el uso de mapas como objetos fijos que representan de manera clara y legible la movilidad de la cotidianidad y llevan a facilitar la abstracción de los conceptos referentes a la interacción social y los imaginarios que convergen en ella. Esto, sin entrar en detalle acerca de las facilidades que aporta a la hora de promover la participación de diversos grupos de personas, pues en últimas, los mapas cumplen con su función de orientar, organizar y generar un lenguaje universal a partir de lo gráfico y lo dialéctico.

\section{Conclusiones}

El territorio es un constructo multidimensional cuyo significado se construye y se consolida permanentemente a partir de los procesos sociales, políticos, comunicacionales, antropológicos y sociológicos, entre otros. Definirlo conlleva pensar en su naturaleza cambiante, la cual debe considerar los cambios propios de los fenómenos que en él ocurren. El territorio, en palabras de Nates (2011), se concibe como un principio organizador de la naturaleza desde el cual se simbolizan las cosas. Dentro de las dimensiones por considerar, se tiene la necesidad de vincular los procesos sociohistóricos y sociopóliticos, pues es a partir de estos que se configura lo que significa el territorio para quienes lo habitan. Aunado a lo anterior, se invita a reconocer la íntima relación entre territorio y la condición espacio-temporal que ha acompañado a este elemento cuando se quiere representarlo y definirlo. Esta condición requiere, además, la vinculación de elementos asociados a ella, como la representación de espacios, lugares y sitios, entre otros.

Dado el carácter anteriormente mencionado, un elemento importante dentro de la comprensión del territorio son las emociones y el vínculo emocional que se establece con él. Estas emociones están ligadas a la construcción de identidad tanto personal como social, al establecimiento de relaciones, a la construcción de comunidad y de sentido de comunidad y a las experiencias y vivencias, las cuales pasan a formar parte de lo que para cada sujeto representa del espacio que habita. Estas representaciones sociales y culturales, son tanto individuales como colectivas o comunitarias y van marcando la ruta de lo que se requiere para lograr aproximarse a lo que en realidad describe al territorio. Aquí es necesario resaltar la postura de Fernandes (2012), cuando al hablar de conflictividad y tipología de territorio denota la importancia de las relaciones establecidas en los espacios habitados para la configuración de lo que conocemos como territorio.

El vínculo emocional que se establece con el territorio, permite la construcción de elementos que, en ocasiones, pueden servir como herramientas o estrategias para que quienes lo habitan logren mejorar su calidad de vida o simplemente resistir a eventos como fenómenos naturales, violencias y conflicto armado, entre otros. Del establecimiento de este vínculo emocional surgen valores como la solidaridad, valor que se ha convertido en una estrategia de gran magnitud para resistir la violencia y generar identidad, lazos en comunidad y una marcada construcción colectiva y comunitaria (Moreno y Mornan, 2015). En este sentido, habrá que profundizar en lo que Fernandes (2017) denomina territorios materiales e inmateriales, para comprender a profundidad el sentido de las relaciones y de las conflictividades gestadas en estos espacios, desde lo cual podrían generarse interesantes aportes a la comprensión de los vínculos emocionales allí establecidos.

Hablar de vínculos con el territorio lleva a abordar el concepto de territorialización, proceso que se da en la apropiación que un sujeto o grupo social hace del lugar que habita, el cual carga de significados -la semantización del espacio- producidos en las disputas, 
acuerdos, estipulaciones y resistencias propias de la vida cotidiana. En el entramado de la vida social se observan capacidades desiguales de apropiación de un espacio, que corresponden a un ordenamiento jerárquico de la vida, disputas por el territorio donde están inmersas relaciones de poder las cuales refuerzan como se puede ser, y estar en un lugar, además de esas otras formas que estarán al margen de la sociedad (Pelli, 2020).

Lo anterior quiere decir que los procesos de territorialización materializan y visibilizan las disímiles formas de habitar un lugar y configuran espacialidades, objetualidades, corporalidades y subjetividades no ajenas a las experiencias, comportamientos, sentires y emociones propias y colectivas del sujeto en el territorio físico-geográfico, político, social y cultural. Esto hace de ellos procesos dinámicos y en constante transformación que constituyen una relación dialéctica entre la reterritorialización y la construcción de un vínculo por un nuevo territorio, y la desterritorialización, desaparición, olvido y pérdida del sentir un lugar propio. Además de determinar el rechazo por ciertos lugares y quienes habitan allí, -topofobias- y el enganche con otros -topofilias-.

Los ejercicios de cartografía se constituyen en escenarios de enunciación frente a lo que sucede en los territorios, pues hablar de los elementos físicos, los cambios surgidos y las relaciones de poder que se dan en el suelo por tensiones entre lo público y lo privado, lleva a hacer reflexiones políticas y esto trae consigo la articulación de diferentes sectores para la transformación, tanto sobre lo visible como sobre las representaciones que se tejen con respecto al territorio.

También cabe resaltar que el territorio y la temporalidad tienen una relación importante que surge en las cartografías al momento de indagar por las memorias, los cambios en el tiempo, las condiciones actuales y el futuro de un sujeto o grupo social. Los sucesos históricos afectan la manera como los participantes se vinculan con el territorio y el sentido de pertenencia por ellos. Pensar en la transformación conlleva, entonces, hablar del pasado, de la actualidad y de una proyección hacia el futuro.

En el contexto colombiano, lo anterior lleva a abordar cuestiones como el desplazamiento forzoso consecuencia de la violencia sociopolítica, el cual pone en evidencia unas maneras particulares de relación entre los sujetos o grupos víctimas y el territorio. Las cartografías, logran captar las añoranzas del pasado, los arraigos, desarraigos, los apegos y los deseos de retorno que existen en comunidades originalmente rurales o indígenas, que obligados a causa de la guerra o por la búsqueda de oportunidades en la ciudad habitan otros espacios, lo cual hace visible la manera desigual como se configuran los procesos de desterritorialización y reterritorialización entre unos grupos que tienen el control del proceso, y otros en los que este es resultado del despojo y la búsqueda de condiciones mínimas de existencia.

El conocimiento del territorio y la identificación de las emociones, memorias y experiencias compartidas, llevan a constituir la territorialización de los espacios físicos y no físicos. Las cartografías sociales contribuyen a hacer visible las múltiples relaciones de los sujetos con el territorio y son instrumentos que facilitan procesos de representación, reconocimiento y empoderamiento de quienes cohabitan un lugar e incluso, en algunos casos, posibilitan nuevos vínculos con el territorio, cambios en las prácticas sociales y transformación de las realidades de individuos y grupos sociales.

\section{Referencias}

Aubán, M. (2017). Dignity in the margins. Affective approaches to the informal city. Revista INVI, 32(91), 67-89. https://doi.org/10.4067/s0718-83582017000300067 
Barragán, D. (2016). Cartografía social pedagógica: entre teoría y metodología. Revista Colombiana de Educación, (70), 247-285. https://doi.org/10.17227/01203916.70rce247.285

Barragán, A. (2019). Cartografía social: lenguaje creativo para la investigación cualitativa. Sociedad y Economía, 36, 139-159. https://doi.org/10.25100/sye.v0i36.7457

Bernal, M. (2012). Territorialidad nasa en Bogotá: apropiación, percepción y sentido de lugar. Cuadernos de Geografia: Revista Colombiana de Geografia, 21(1), 83-98. https://doi.org/10.15446/ rcdg.v21n1.30695

Berroeta, H., Pinto de Carvalho, L., Di Masso, A., \& Ossul, M. I. (2017). Apego al lugar: una aproximación psicoambiental a la vinculación afectiva con el entorno en procesos de reconstrucción del hábitat residencial. Revista INVI, 32(91), 113-139. https://doi.org/10.4067/ s0718-83582017000300113

Betancurth, D., Vélez, C., y Sánchez, N. (2020). Cartografía social: construyendo territorio a partir de los activos comunitarios en salud. Entramado, 16(1), 138-151. Recuperado de https:// revistas.unilibre.edu.co/index.php/entramado/article/view/6081

Bendini, M. (2011). Movilidad del capital y del trabajo: territorialización "multiforme" en regiones extrapampeanas. Pampa: Revista Interuniversitaria de Estudios Territoriales, 7, 9-30. Recuperado de https://dialnet.unirioja.es/servlet/articulo?codigo $=4000541$

Carballeda, A. (2017). Cartografías Sociales: lenguaje y territorio. Una aproximación desde La Intervención en lo Social. Revista Perspectivas: Notas sobre intervención y acción social, 29, $145-$ 153. https://doi.org/10.29344/07171714.29.1088

Cejas, N., Martinez, V. y Vanoli, F. (2017). El lugar de los artefactos en procesos sociales. Reflexiones sobre una experiencia de tecnología social en Bariloche, Argentina. PAAKAT: Revista de Tecnologia y Sociedad, 7(13), 1-21. Recuperado de http://www.scielo.org.mx/pdf/prts/ v7n13/2007-3607-prts-7-13-00001.pdf

Covarrubias, F., y Cruz, M. (2019). La apropiación paisajística del territorio: una disputa epistemológica. Cinta de Moebio, 64, 82-98. https://doi.org/10.4067/S0717-554X2019000100082

Cuesta, Ó., y Mélendez, S. (2017). Comunicación urbana: antecedentes y configuración de líneas de investigación en América Latina y Espańa. Territorios, (37), 205-228. https://doi. org/10.12804/revistas.urosario.edu.co/territorios/a.4889

Díaz, J. (2015). Economías solidarias y territorio: hacia un análisis desde la complejidad. Otra Economía, 9(17), 1-21. https://doi.org/10.4013/otra.2015.917.02

Díaz, J. (2014). Economias solidarias y territorio: hacia una construcción compleja o un análisis desde la complejidad. Trabajo presentado en el Seminario Internacional "La búsqueda de alternativas al capital en el siglo XXI. Miradas etnográficas", ITESO- Universidad Jesuita de Guadalajara, Guadalajara, México. Recuperado de http://hdl.handle.net/11117/1544

Feldman, J. (2017). Arte contemporáneo: Temporalidad, territorialización y circulación. Boletín de Arte, (38), 87-96. https://doi.org/10.24310/BolArte.2017.v0i38.3222

Fernandes, B. (2012). Movimentos socioterritoriais e movimentos socioespaciais: contribuiçáo teórica para uma leitura geográfica dos movimentos sociais. Revista Nera, 8(6), 24-34. https:// doi.org/10.47946/rnera.v0i6.1460

Fernandes, B. (2017). Territorio y soberanía alimentaria. Revista Latinoamericana de Estudios Rurales, 2(3), 22-38. Recuperado de http://www.ceil-conicet.gov.ar/ojs/index.php/revistaalasru/ article/view/114/111

Garavito, L., y De Urbina, A. (2019). El borde no es como lo pintan. El caso del borde sur de Bogotá, D. C. Territorios, (40), 83-117. https://doi.org/10.12804/revistas.urosario.edu.co/ territorios/a.6350

Gaviria, M. (2020). Territorialidades en la ciudad-región Eje Cafetero, Colombia. Territorios, (42), 1-24. https://doi.org/10.12804/revistas.urosario.edu.co/territorios/a.7012 
Giménez, G. (2005). Territorio e identidad. Breve introducción a la geografía cultural. Trayectorias, 7(17), 8-24. Recuperado de https://www.redalyc.org/articulo.oa?id=60722197004

Habegger, S., y Mancila, I. (2006). El poder de la cartografia social en las prácticas contrahegemónicas o la cartografía social como estrategia para diagnosticar nuestro territorio. BEU Biblioteca digital de extensión universitaria. Recuperado de http://beu.extension.unicen.edu.ar/xmlui/ handle/123456789/365

Haesbaert, R. (2013). Del mito de la desterritorialización a la multiterritorialidad. Cultura y representaciones sociales, 8(15), 9-42. Recuperado de http://www.scielo.org.mx/pdf/crs/v8n15/ v8n15a1.pdf

López, L., y Figueroa, M. (2013). Artes visuales y procesos de territorialización en contextos de narcoviolencia. Argumentos (México, D.F), 26(71), 169-192. Recuperado de http://www. scielo.org.mx/pdf/argu/v26n71/v26n71a8.pdf

Manzanal, M. (2014). Desarrollo. Una perspectiva crítica desde el análisis del poder y del territorio. Realidad económica, 283, 17-48. Recuperado de http://ri.conicet.gov.ar/handle/11336/35139

Medel, M., y Montre, V. (2018). Imaginarios urbanos sobre topofilia y topofobia: el caso de la ciudad de Chiguayante, Región del Biobío. Revista de Urbanismo, (38), 1-16. https://doi. org/10.5354/0717-5051.2018.48702

Mendes, G. (2014). Uso do território para inovação. Mercator. Revista de Geografia Da UFC, 2 (13), 53-60. Recuperado de https://www.scielo.br/pdf/mercator/v13n2/1676-8329-mercator-13-02-0053.pdf

Miñana, C. (2008). Música y fiesta en la construcción del territorio nasa (Colombia). Revista Colombiana de Antropologia, 44(1), 123-155. https://doi.org/10.22380/2539472X.1056

Monnet, J. (2013). El territorio reticular. En B. Nates (ed.). Enfoques y métodos en estudios territoriales, Manizales : RETEC/Doctorado de estudios territoriales de la Universidad de Caldas (pp. 137-167). Centre pour la Communication Scientifique Directe. Recuperado de https://halshs. archives-ouvertes.fr/halshs-00533584v2

Moreno, V., y Mornan, D. (2015). ¿Y el derecho a la ciudad? Aproximaciones al racismo, la dominación patriarcal y las estrategias feministas de resistencia en Cali, Colombia. Revista CS, (16), 87-108. https://doi.org/https://doi.org/10.18046/recs.i16.1987

Montenegro, C. (2019). Cartografias colectivas como espacios de reflexión visual: territorios, experiencias y contextos. Trabajo presentado en IV congreso internacional de investigación en artes visuales ANIAV 2019 imagen [n] visible], Aniav, Asociación Nacional de Investigación en Artes Visuales, Valencia, España. https://doi.org/10.4995/aniav.2019.9541

Nates, B. (2011). Soportes teóricos y etnográficos sobre conceptos de territorio. Co-Herencia, 8(14), 209-229. Recuperado de http://www.scielo.org.co/pdf/cohe/v8n14/v8n14a09.pdf

Osorio, H., y Rojas, E. (2011). La cartografía como medio investigativo y pedagógico. Dearq, 9, 30-47. https://doi.org/10.18389/dearq9.2011.05

Osorio, S., y Vergara, M. (2016). La cartografía emocional y los paisajes sonoros: una manera diferente de entender la ciudad. HojaLata, 8, 35-46. https://revistasum.umanizales.edu.co/ ojs/index.php/hojalata/article/view/1779/1871

Pájaro, D., y Tello, E. (2014). Fundamentos epistemológicos para la cartografía participativa. Etnoecológica, 10 (1), 1- 20. Recuperado de https://www.researchgate.net/publication/296665874_Fundamentos_epistemologicos_para_la_cartografia_participativa

Pelli, M. (2020). Las fronteras del habitar en el espacio urbano. Prácticas de apropiación. Bitácora Urbano Territorial, 30(1), 103-114. https://doi.org/10.15446/bitacora.v30n1.70106

Pérez, L., Ganter, R., y Baumgartner, M. (2018). Cartografías participativas y producción de datos sociales en escenarios patrimoniales. Posibilidades de reutilización comunitaria de las "Ruinas 
de Enacar", sector Chambeque, Lota, (Chile). Urbano, 21 (38), 36-47. https://doi.org/10.22 320/07183607.2018.21.38.03

Portilla, F. (2014). Memorias taciturnas del desarraigo y la territorialización. Sophia, 10(1), 39-49. Recuperado de https://revistas.ugca.edu.co/index.php/sophia/article/view/216

Quintana, J. (2019). Territorio, memoria y género: significados de la participación política de mujeres en Atenco, México. Revista Ambiente e Sociedade, 22, 1-18. https://doi.org/10.1590/18094422asoc0116r1vu19L4AO

Quińonez, M. (2011). La manera cultural: entre el desarraigo y la territorialización: una experiencia de cartografía social en la zona de Bajamar -Isla de Cascajal Buenaventura-. Entramado, 7(2), 156-171. Recuperado de https://revistas.unilibre.edu.co/index.php/entramado/article/ view/3407

Rojas, C. (2018). Emociones y sentimiento de pertenencia de los territorios del Estado-nación: el desprecio y el caso colombiano. Revista desenvolvimento, fronteiras e cidadania, 2(1), 32-37. Recuperado de https://core.ac.uk/download/pdf/234767966.pdf

Santos da Rocha, A. (2013). Território como representação. Mercator - Revista de Geografia Da UFC, 12(29), 139-153. Recuperado de https://www.redalyc.org/pdf/2736/273629350011.pdf

Skewes, J., Trujillo, F., y Guerra, D. (2017). Traer el bosque a los domicilios. Transformaciones de los modos de significar el espacio habitado. Revista INVI, 32(91), 23-64. Recuperado http:// revistainvi.uchile.cl/index.php/INVI/article/view/1224

Stamm, C., y Aliste, E. (2014). El aporte de un enfoque territorial al estudio de los conflictos socio-ambientales.F@ro: revista teórica del Departamento de Ciencias de la Comunicación, 2(20), 66-78. Recuperado de http://dialnet.unirioja.es/servlet/articulo?codigo=4926084\&i nfo=resumen\&idioma $=\mathrm{ENG}$

Ther, F., y Valderrama, J. (2012). Dinámicas territoriales en asentamientos de pescadores artesanales: economías, experiencias y conflictos. El caso de Guabún y Puñihuil en la Comuna de Ancud, Chiloé. CUHSO. Cultura - Hombre - Sociedad, 22 (1), 61-94. https://doi.org/10.7770/ cuhso-v22n1-art355

Tobasura, D., Gurri, F., Blanco, G., y Schmook, B. (2019). Enredando bosques y comunidades: territorialización de REDD+ en el ejido Felipe Carrillo Puerto, México. Cuadernos de Desarrollo Rural, 15(81), 1-18. https://doi.org/10.11144/javeriana.cdr15-81.ebct

Vélez, I., Rátiva, S., y Varela, D. (2012). Cartografía social como metodología participativa y colaborativa de investigación en el territorio afrodescendiente de la cuenca alta del río Cauca. Cuadernos de Geografia: Revista Colombiana de Geografia, 21(2), 59- 73. https://doi. org/10.15446/rcdg.v21n2.25774

Vergara, N. (2012). Significación social y territorio: aproximaciones epistemológicas. Revista Lider, 21, 9-18. Recuperado de https://dialnet.unirioja.es/servlet/articulo?codigo=4960559

Vite, M. (2011). La territorialización de la política urbana y social: reflexiones generales desde el pensamiento sociológico. Convergencia, 18(57), 185-208. Recuperado de http://www.scielo. org.mx/pdf/conver/v18n57/v18n57a8.pdf

Yory, C. M. (2017). El concepto de topofilia entendido como teoría del lugar. En Lugar y territorio: Una aproximación multidimensional a la noción de espacio habitado para pensar y habitar la ciudad del siglo XXI a partir del concepto de topofilia (1a ed.). Universidad Piloto de Colombia. https://doi.org/10.2307/j.ctv8j5sf.8

Zapata, M. (2008). Territorialización del delito: Aproximación conceptual para el abordaje del fenómeno en la ciudad. Revista Criminalidad, 50(1), 333-350. Recuperado de http://www.scielo.org.co/scielo.php?script=sci_arttext\&pid=S1794-31082008000100010\&lng=en\&tlng=es 